INTRODUCTION

\title{
Facilitating the critical process in tobacco control
}

\author{
C P Wen
}

Tobacco Control 2005;14(Suppl I):i1-i3. doi: 10.1136/tc.2005.012161

孟子日: 不為也, 非不能也.

\author{
Mencius, a disciple of Confucius: You do not perform, not \\ because you are not able to
}

E merging as a rapidly developing country, Taiwan has the resources to invest in furthering tobacco control and fostering a paradigm shift in making smoking socially unacceptable. The growing calamity of tobacco related deaths and the associated economic losses could easily justify a much larger investment, and yet, the "business as usual" mentality persists, with uninspired goals, resulting in slow and limited progress. Incremental improvement is often hailed as a satisfactory achievement. What has been missing in Taiwan, as in many Asian nations, is the research based political commitment to facilitate the critical process in tobacco control. How does one make such a political commitment among competing priorities? What motivates policymakers to make such a decision? These are burning questions for Taiwan, at the crossroads of tobacco control. Much of that decision is not necessarily rational or evidence based, but rather reflects the reality that, in emerging democratic societies like Taiwan, the ballot box is king and voters persuade policymakers. ${ }^{1}$ As shown in fig 1 , in contrast to the western countries, where a top down approach is usually feasible, Taiwan requires a bottom up approach. An essential element in the process is to have, first of all, an enlightened public who understand the seriousness of smoking hazards, support the case for urgent action, and vote for politicians willing to make the needed commitment to tobacco control.

TRANSLATING RESEARCH INTO ACTION Research presented in this issue is ready to be translated into action and communicated to the public. Smokers, more likely to come from lower socioeconomic classes and from the less educated, ${ }^{2}$ need to be convinced, in plain languages, of the hazards of smoking ${ }^{3-5}$ and the benefits of cessation. ${ }^{6}$ At the same time, environmental and economic pressures should be exerted, and incentives provided, to help smokers quit. Because of having relatively few ex-smokers, improving the effectiveness of smoking cessation is extremely important and is pivotal for the success of tobacco control in Taiwan. ${ }^{78}$ Nonsmokers, constituting three quarters of the voting adults, ${ }^{2}$ should be well informed of the hazards of second hand smoking, on the need to reduce the inequality created by smoking, ${ }^{9}{ }^{10}$ and on the economic and psychological burden imposed on family members and friends of smokers who suffered smoking related diseases. As smokers are outnumbered three to one by non-smokers in Taiwan, non-smokers, at least in theory, should prevail in public referendum on tobacco control issues. Learning that the revenue from a large cigarette tax can substantially benefit non-smokers as well as smokers will further strengthen public support. ${ }^{11}$ Support from professionals, especially those in the medical profession, is particularly important in Asian countries. ${ }^{12}$ Asian countries have long invested almost exclusively in preventing youth from smoking, and shied away from the root of the youth problem-adult smoking. ${ }^{7}$ To turn the corner on tobacco control, medical professionals must renew their commitment and adopt a new paradigm, particularly assuming a vastly different role in the promotion of cessation. By being more assertive and proactive, they can influence the public opinion and change the position of the decision makers. On a common sense issue like tobacco control, high political commitment cannot be demonstrated unless supported by the public, and advocated by the professionals. Purposefully or not, cigarette prices in Taiwan have been kept extremely low, ${ }^{13}$ and any proposal to increase the tax substantially has been met with little enthusiasm by policymakers, sensing there would be vocal opposition from the voting public.

\section{SETTING AMBITIOUS GOALS}

Once a political commitment is made, further scientific pursuit is continually required to provide a high quality evidence for effective tobacco control intervention. Selecting the right problems to solve, rather than taking a shotgun approach, is a challenge for Taiwan. By stretching the imagination and setting ambitious goals, ${ }^{14}$ coupled with published timelines, such as "halving the smoking rates in the next ten years", reflects the urgency of and commitment to those priorities. The priorities described in this issue include actions such as sharply raising cigarette tax up to fivefold in five years, ${ }^{15}$ seeking damage compensation from tobacco companies for the deceptions and cover ups, ${ }^{16-18}$ offering user friendly, incentive-rich cessation services, applying tobacco control efforts to betel quid control in an innovative and aggressive way, ${ }^{19}$ embracing and exceeding the stipulations contained in the Framework Convention on Tobacco $\mathrm{Control}^{20}$ along with other legislative initiatives to make all homes smoke-free, and building capacity and infrastructure for tobacco control. ${ }^{21}$ 


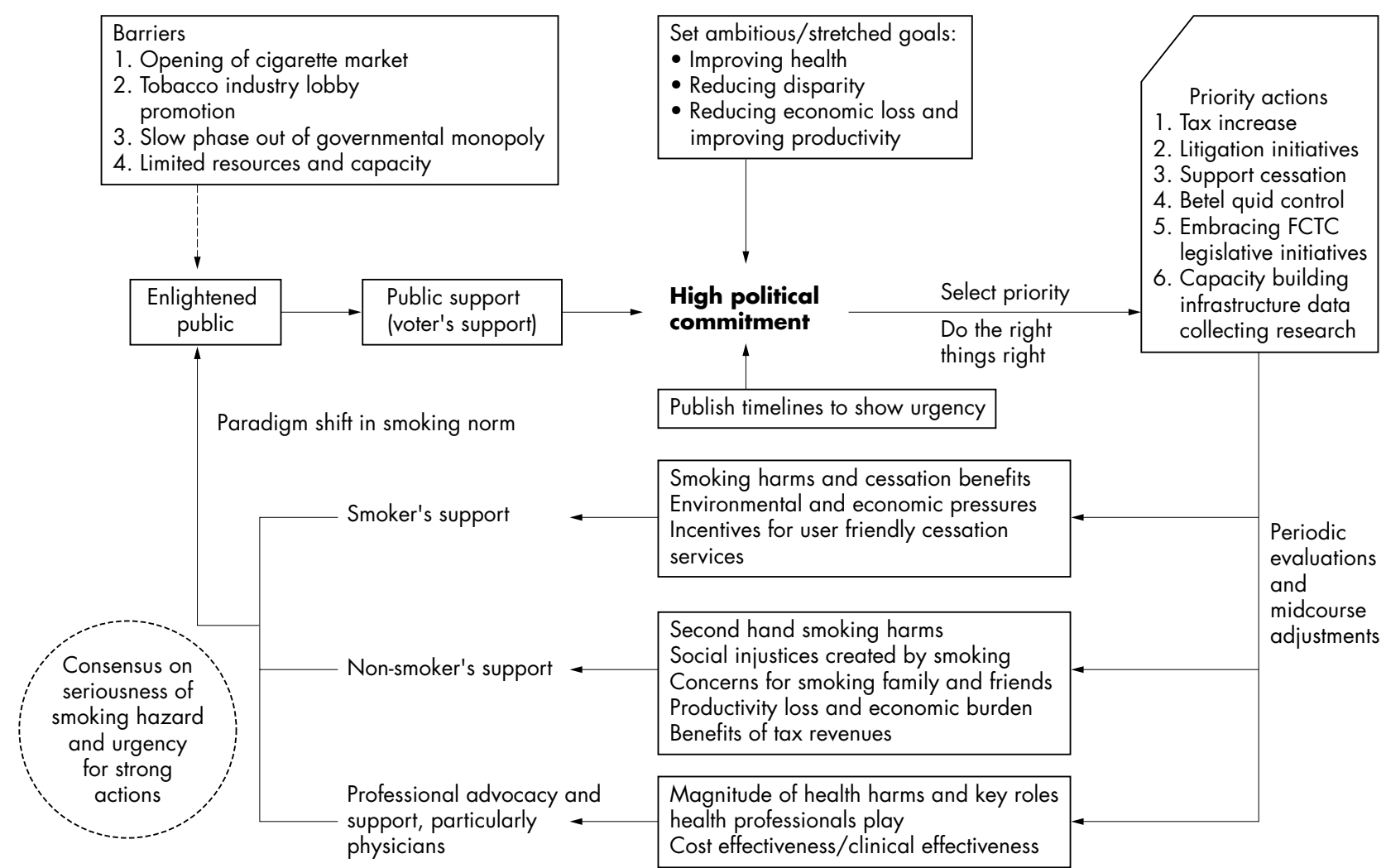

Figure 1 A bottom-up decision making model illustrating how political commitments on tobacco control can be facilitated in an emerging democratic society where the ballot box is king.

The evidence gathered in this issue should be packaged and written into attractive newsworthy stories. Newspaper headlines highlighting these research results and priority action items listed is the first step towards those goals.

In Asian countries, programmatic evaluation has been relatively weak or often perfunctory, ${ }^{22}{ }^{23}$ and yet, the degree of success in tobacco control rests on the use of scientific evidence in making mid-course adjustments. Usually content with incremental improvement in a non-competitive business environment, workers in public health have seldom questioned activities within tobacco control, rarely asking whether the best solutions were sought or even the right problems were chosen. In part, this is due not so much to the lack of objective data for assessment, but to the failure to take advantage of existing, available data. Research from Taiwan demonstrates the value and the power of making use of the available data. Capacity or infrastructure building becomes important, since the absence of credible evaluation or the lack of financial accountability can easily hamper further investment in tobacco control.

\section{OVERCOMING THE CONSEQUENCES OF MARKET OPENING}

The negative impact of opening the cigarette market in 1987 caught Taiwan by surprise, ${ }^{24}$ and Taiwan was ill-prepared for the profound, untoward consequences that the public long endured. The opening increased consumption, not only in cigarettes but also in betel quid. Fifteen years later, betel quid consumption has increased fivefold and oral cancer deaths have more than quadrupled, outpacing the rates in most other countries. ${ }^{19}$ As phasing out of the monopoly system stretched out for nearly two decades, the Taiwan government found itself in an awkward position of waging an all out war against tobacco, but still remaining the largest producer of cigarettes in the country. Nevertheless, the cigarette market opening legitimised the Department of Health in its anti-foreign tobacco position. Shortly afterwards, it targeted all cigarettes, not just foreign products. Such a reversal of governmental position was once considered a bittersweet outcome of the opening. However, the overall efforts continued to be compromised, as conflicts continued amid inter-cabinet negotiations between concern for health of the public and concern for the best management of the tobacco business, with the government being by far the largest shareholder in the domestic tobacco company. The market opening also saw the emergence of the powerful tobacco lobby, ${ }^{25}$ achieving their goals behind the scene. Threat of litigation seems to have proven itself as an effective way to keep the industry behaviour at least partially in check in the USA, and this strategy is for Taiwan to master as one of the lessons from the market opening. ${ }^{26}$

The serious complications caused by the market opening will only be overcome, through the growing understanding and support from an enlightened public, by a heightened political commitment by the decision makers. Sustaining the public support requires the continuing research based evidence, further unveiling of the secrets of the domestic industry, ${ }^{16} 27$ and the assistance from the attention getting investigative reporting. ${ }^{28}$

\section{BRIDGING THE GAP}

This issue is a small step in bringing such scientific evidence to the public and in bridging the gap between science and the policymaking process. The next step is to catalyse widespread public support to achieve the political commitment of the policymakers. This commitment is needed, not merely for making limited, incremental improvement, but for implementing ambitious, breakthrough strategies and robust, 
enduring measures, resulting in a paradigm shift in the social acceptability of smoking and a sharp drop in smoking populations. A giant leap forward in tobacco control is completely possible, but the burning question is whether we can mobilise a political will to commit to that goal. You can do it Taiwan! You can do it Asian countries!

\section{ACKNOWLEDGEMENT}

The NHRI, a non-governmental organisation in Taiwan, has been a major supporter for resources in this research and for making this issue possible.

\section{REFERENCES}

1 Sheng E. Let the people's votes decide policy. Taipei Times 2001

2 Wen CP, Levy DT, Cheng TY, et al. Smoking behaviour in Taiwan, 2001. Tobacco Control 2005; 14(suppl I):i51-5.

3 Wen CP, Tsai SP, Chen CJ, et al. The mortality risks of smokers in Taiwan - part I: cause-specific mortality. Prev Med 2004;39:528-35.

4 Wen CP, Tsai SP, Cheng TY, et al. Excess injury mortality among smokers: a neglected tobacco hazard. Tobacco Control 2005; 14(suppl I):i28-32.

5 Wen CP, Tsai SP, Chen C-J, et al. Smoking attributable mortality for Taiwan and its projection to 2020 under different smoking scenarios. Tobacco Control 2005; 14(suppl I):i76-80.

6 Wen CP, Cheng TY, Lin CL, et al. The health benefits of smoking cessation for adult smokers and for pregnant women in Taiwan. Tobacco Control 2005; 14(suppl I):i56-61

7 Wen CP, Tsai SP, Cheng TY, et al. Role of parents and peers in influencing the smoking status of high school students in Taiwan. Tobacco Control 2005; 14(suppl I):i10-15.

8 Wen CP, Cheng TY, Hsu CC, et al. Preventing youth smoking: lessons learned from the changing smoking rates after the tobacco market opened among APACT counteries. Proceeding of The 7th Asia Pacific Conference on Tobacco or Health. Gyeongiu, Korea, 2004.

9 Healton C, Nelson K. Reversal of misfortune: viewing tobacco as a social justice issue. Am J Public Health 2004;94:186-91.

10 Cheng TY, Wen CP, Tsai SP, et al. Reducing health disparity in Taiwan: quantifying the role of smoking. Tobacco Control 2005; 14(suppl I):i23-7.

11 Chaloupka FJ, Hu TW, Warner KE, et al. The taxation of tobacco products. In: Chaloupka FJ, Jha P, eds. Tobacco control in developing countries. New York: Oxford University Press, 2000
12 Anon. Smoking and health: a physician's responsibility. A statement of the joint committee on smoking and health. American College of Chest Physicians, American Thoracic Society, Asia Pacific Society of Respirology, Canadian Thoracic Society, European Respiratory Society, International Union Against Tuberculosis and Lung Disease. Eur Respir J 1995:8:1808-11.

13 Guindon GE, Tobin S, Yach D. Trends and affordability of cigarette prices: ample room for tax increases and related health gains. Tobacco Control 2002; 11:35-43.

14 Green LW, Eriksen MP, Bailey L, et al. Achieving the implausible in the next decade's tobacco control objectives. Am J Public Health 2000;90:337-9.

15 Levy DT, Wen CP, Cheng DTY, et al. Increasing taxes to reduce smoking prevalence and smoking attributable mortality in Taiwan: results from a tobacco policy simulation model. Tobacco Control 2005;14(suppl I):i45-50.

16 Wen CP, Chen T, Tsai T-T, et al. Are marketing campaigns in Taiwan by foreign tobacco companies targeting young smokers? Tobacco Control 2005; 14(suppl I):i38-44

17 Tsai SP, Wen CP, Hu SC, et al. Workplace smoking related absenteeism and productivity costs in Taiwan. Tobacco Control 2005; 14(suppl I):i33-7.

18 Yang MC, Fann CY, Wen CP, et al. Smoking attributable medical expenditures, years of potential life lost, and the cost of premature death in Taiwan. Tobacco Control 2005;14(suppl I):i62-70.

19 Wen CP, Tsai SP, Cheng TY, et al. Uncovering the relation between betel quid chewing and cigarette smoking in Taiwan. Tobacco Control 2005; 14(suppl I):i16-22.

20 Guindon GE, de Beyer J, Galbraith S. Framework convention on tobacco control: progress and implications for health and the environment. Environ Health Perspect 2003:111:A262-3.

21 World Health Organization. Building blocks for tobacco control: a handbook. Geneva: WHO, 2004

22 Chapman S. Re: TC and the global tobacco epidemic. Tob Control-eLetters for Chapman 2005;13:321-2.

23 Sato H. Policy and politics of smoking control in Japan. Soc Sci Med 1999;49:581-600.

24 Wen CP, Cheng TY, Eriksen MP, et al. The impact of cigarette market opening in Taiwan. Tobacco Control 2005; 14 (suppl I):i4-9.

25 US Department of Health and Human Services. Reducing tobacco use: a report of the Surgeon General. Atlanta, Georgia: US Department of Health and Human Services, Centers for Disease Control and Prevention, National Center for Chronic Disease Prevention and Health Promotion, Office on Smoking and Health, 2000:61-85

26 Daynard R. Why tobacco litigation? Tobacco Control 2003:12:1-2.

27 Mackay JM. The tobacco industry in Asia: revelations in the corporate documents. Tobacco Control 2004;13(suppl II):ii1-3.

28 Mann M. The Insider. (Movie). USA, 1999.

\section{A NEW BOOK}

\section{The Taiwan Tobacco Atlas}

\section{This book will play a significant role in keeping the importance of tobacco control in the public eye..."-Professor Michael Eriksen, co-} author of WHO's The Tobacco Atlas

"I was touched by its relevancy, its comprehensiveness and its thought provoking contents" - Professor Ming-Liang Lee, Former Minister of Health, Taiwan

This Taiwan Tobacco Atlas is unique and sets a precedent in that it has crystallised and reduced complex, evidence based data into half graphic and half clipboard styled presentations, appealing to the serious readers and attractive to concerned smokers. The book demonstrates how an emerging nation can systematically and critically review the various aspects of tobacco control issues based on research results, fully capitalising on an old Chinese saying "A picture is worth a thousand words". Taiwan is setting an example for other nations to emulate in reaching out to the public to gain understanding and support. The colourful book is a joy to read and is fun just to flip through.

To see the table of contents or to order a copy, visit the website: http://atlas.nhri. org.tw/tobacco

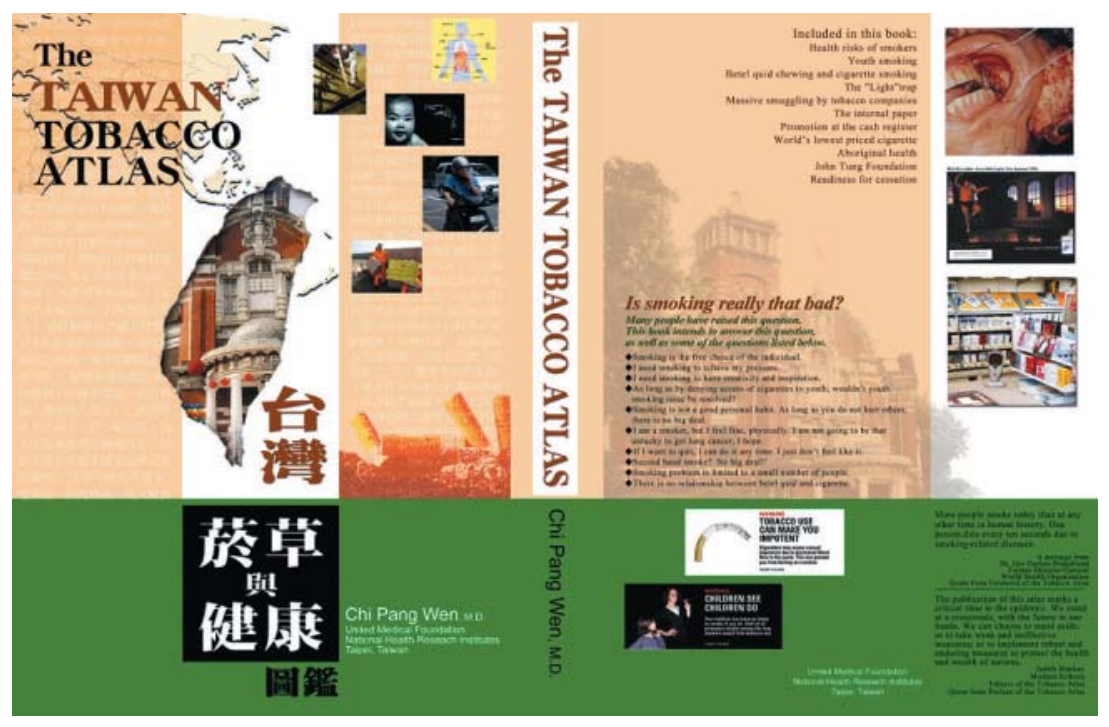

